\title{
Пленочные конденсаторы WIMA: электронные компоненты с безупречной репутацией
}

\author{
М. Соколов ${ }^{1}$, В. Ежов
}

УДК 621.319.4 | ВАК 05.27.01

\begin{abstract}
Основанная в 1948 году компания WIMA - ведущий производитель высококачественных пленочных конденсаторов различных типов: от SMD и выводных до блоков суперконденсаторов. Благодаря своим характеристикам и высокой надежности конденсаторы WIMA завоевали популярность среди разработчиков потребительской и промышленной электроники высочайшего уровня. Все подразделения WIMA, в том числе производственные, расположены в Германии, что говорит об исключительном качестве изделий. Продукция компании предназначена для применения в широком спектре приложений, в частности в силовой и автомобильной электронике, системах освещения, медицинском оборудовании, телекоммуникациях. Наряду со стандартными изделиями компания предлагает кастомизированные решения, изготавливаемые по требованиям заказчика. Рассмотрим номенклатуру компонентов, выпускаемых компанией WIMA, их особенности и сферы применения.
\end{abstract}

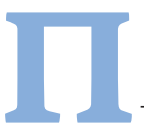

родуктовая линейка пленочных конденсаторов компании WIMA развивалась по пути миниатюризации и совершенствования технологии: уменьшения межвыводного расстояния, применения все более тонких полимерных пленок, внедрения новых технологий корпусирования и других инновационных решений. Это позволило достичь высоких характеристик - низкой самоиндукции, малых значений тангенса угла потерь в диэлектрике, высокой способности к самовосстановлению, длительного срока службы и др. Сегодня в ассортимент продукции WIMA входят следующие классы устройств: SMD-конденсаторы, миниатюрные выводные конденсаторы с шагом выводов 2,5 мм, фольгированные, металлопленочные, импульсные, помехоподавляющие, фильтрующие, снабберы, GТО-конденсаторы, конденсаторы для шин постоянного тока DC-Link и силовые блоки на основе суперконденсаторов. Рассмотрим подробнее эти продукты.
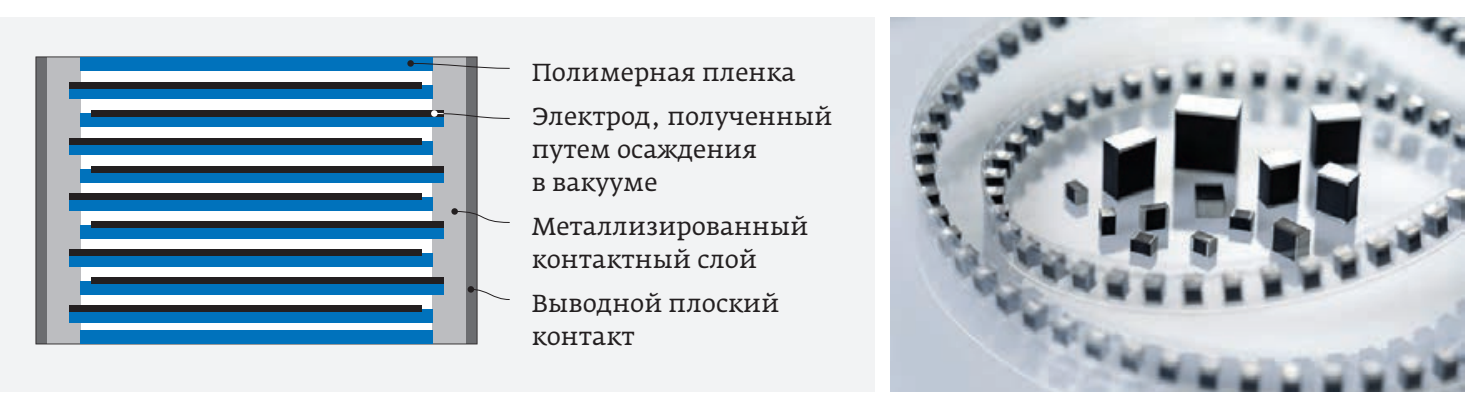

Рис. 1. SMD-конденсатор: слева внутренняя структура; справа внешний вид
SMD-конденсаторы WIMA (рис. 1) в пластиковом корпусе предлагаются в трех вариантах: с диэлектрическими металлизированными пленками из полиэтилентерефталата (РЕT), полиэтиленнафталата (PEN) и полифениленсульфида (PPS). Они пригодны для бессвинцовых процессов пайки в соответствии с RoHS2011 / 65/ EU. Доступны следующие типоразмеры: 1812, 2220, 2824, 4030, 5040 и 6054. Диапазон емкостей - от 0,01 до 6,8 мкФ, номинальные напряжения от 63 до 1000 В. Ассортимент изделий перекрывает практически весь спектр применений обычных выводных пленочныхконденсаторов.

Технология капсулирования SMD-конденсаторов от WIMA обеспечивает ряд преимуществ по сравнению с обычными неинкапсулированными или прессованными конструкциями SMD-конденсаторов:

- защита емкостного элемента от механических и тепловых перегрузок в процессе пайки;

«Золотой шар».бренд-менеджер, Sokolov@zolshar.ru. 


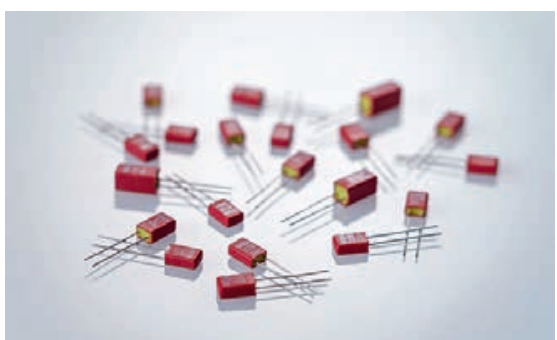

Рис. 2.

Миниатюрные пленочные конденсаторы с шагом выводов 2,5 MM

- отсутствие риска появления внутреннихтрещин или отрыва контактов благодаря эластичности конструкции;

- отсутствие риска расслоения благодаря полноразмерным металлизированным соединительным SMD-площадкам;

- огнестойкое пластиковое покрытие, соответствующее стандарту UL 94 V-0.

SMD-конденсаторы WIMA, рассчитанные на максимальную температуру от 100 до $140^{\circ} \mathrm{C}$, предназначены для применения в цепях постоянного тока в качестве шунтирующих, развязывающих, блокирующих и фильтрующих компонентов. Изделия инкапсулированы в стойкий к действию растворителей пластиковый корпус, срок их эксплуатации составляет более 300 тыс. ч, а интенсивность отказов не превышает двух фит. Конденсаторы SMD-PPS отличаются от SMD-PET и SMD-PEN низКими значениями коэффициента потерь и диэлектрического поглощения, более высокими рабочими температурами (до $140{ }^{\circ} \mathrm{C}$ ), а также стабильностью емкости при изменении температуры.

Еще одно семейство изделий WIMA - миниатюрные пленочные конденсаторы с шагом выводов 2,5 мм (рис. 2, 3), они предлагаются двух типов: FKP 02 - на основе полипропиленовой пленки (РP) и фольги и MKSO2 - на основе металлизированной пленки из полиэтилентерефталата (РЕТ). Диапазон номиналов емкостей - от 100 пФ до 0,01 мкФ для FKP 02 и от 3300 пФ до 1 мкФ для MKS02. Конденсаторы этих серий рассчитаны на напряжение от 63 до 400 В.
Создание этой самой компактной серии выводных пленочных конденсаторов в мире стало возможным в результате применения ультратонкой полимерной пленки толщиной 0,8 мкм и менее.

Благодаря небольшому расстоянию между выводами пленочные конденсаторы с шагом 2,5 мм отличаются очень низкой самоиндукцией. Для серии FKP 02, которая доступна с малыми допусками (до „2,5\%), характерны очень низкие значения коэффициента потерь и поглощения диэлектрика. Эти конденсаторы подходят для высокочастотных приложений, применяются в схемах выборкихранения, LC-фильтрах, генераторных схемах, аудиооборудовании. Серия MKSO2 предназначена, главным образом, для общего применения в цепях постоянного тока в качестве шунтирующих, развязывающих, блокировочных конденсаторов.

Фольгированные конденсаторы От WIMA с шагом выводов от 5 до 15 мм (рис. 4) доступны в двух версиях: серии FKS2/FKS3 - на основе пленки из полиэтилентерефталата и фольги и серии FKP 2/ FKP 3 - на основе полипропиленовой пленки и фольги. РЕТ-конденсаторы подходят для общих применений, таких как развязка и шунтирование. Рр-конденсаторы используются в высокочастотных приложениях, в частности в резонансных и отклоняющих цепях, источниках питания, генераторах сигналов и аудиотехнике.

В фольгированных конденсаторах, в отличие от конденсаторов с металлизированными обкладками, электроды представляют собой металлическую фольгу. Благодаря малому последовательному сопротивлению эти компоненты отличаются превосходной токонесущей способностью, а также очень высоким сопротивлением изоляции. Хотя конструкция фольгированных конденсаторов (см. рис. 3) обеспечивает меньшие по сравнению с металлизированными номиналы емкостей, ее преимущество улучшенный контакт с электродами из фольги и достаточно высокая мощность передаваемого импульса.

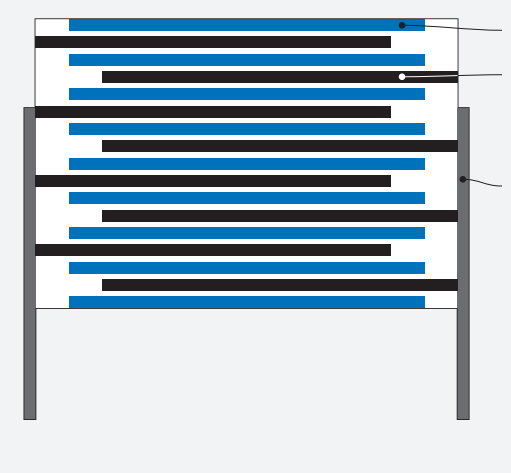

Полимерная пленка электрод из металлизированной фольги Проволочный вывод

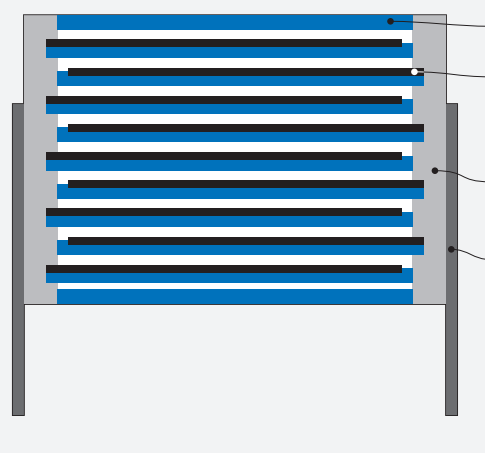

Полимерная пленка Электрод, полученный путем осаждения в вакууме Металлизированный контактный слой Проволочный вывод

Рис. 3. Структура выводного пленочного конденсатора: слева - на основе полипропиленовой пленки и фольги; справа - на основе металлизированной пленки из полиэтилентерефталата 


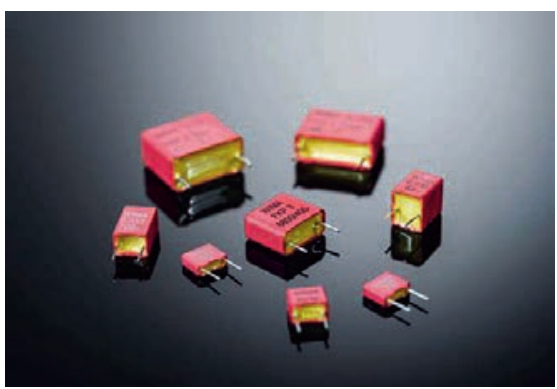

Рис. 4. Фольгированные конденсаторы с шагом выводов от 5 до $15 \mathrm{Mм}$

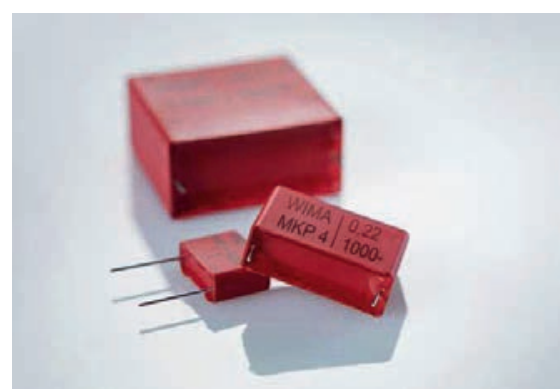

Рис. 5. Металлизированные конденсаторы с шагом выводов от 5 до 52,5 мм

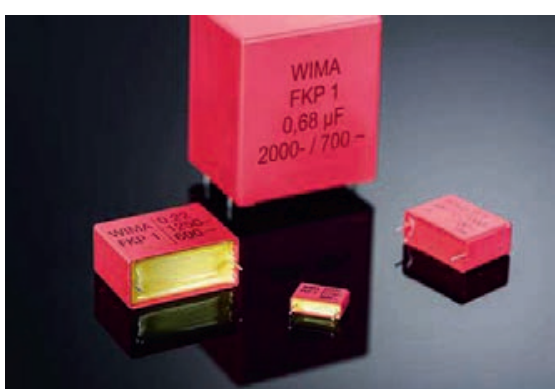

Рис. 6. Импульсные конденсаторы
Для фольгированных конденсаторов с шагом выводов от 5 до 15 мм доступны номиналы емкостей от 33 пФ до 0,22 мкФ, номинальные напряжения - от 63 до 1000 В.

Большой класс устройств производства компании WIMA - металлизированные конденсаторы, в которых в качестве электродов используются тонкие (около 0,03 мкм) слои алюминия, получаемые методом осаждения в вакууме на изолирующую пленку (рис. 5). В случае пробоя ток короткого замыкания вызывает испарение тонкого металлического покрытия вокруг точки отказа и формируется изолирующая область. Конденсатор остается невредимым, то есть обладает свойством самовосстановления. Конструкция металлизированных конденсаторов позволяет достичь весьма высокого соотношения между номиналом емкости и размером компонента.

Металлизированные конденсаторы WIMA с шагом выводов от 5 до 52,5 мм доступны с двумя типами диэлектрика: полиэтилентерефталата и полипропилена. Конденсаторы с РЕТ-диэлектриком (серии MKS2 и MKS4) подходят для общих применений, таких как развязка и шунтирование. Благодаря использованию ультратонкой пленки и отработанной технологии эти устройства отличаются высоким номиналом емкости в очень компактном корпусе. РР-конденсаторы (серии МКР 2, МКР 4С и МКР 4) предназначены для высокочастотных приложений. Для металлизированных конденсаторов с шагом выводов от 5 до 52,5 мм доступны номиналы емкостей от 1000 пФ до 680 мкФ и номинальные напряжения от 50 до 2000 В.

По запросу заказчика могут быть поставлены 4-выводные версии металлизированных конденсаторов в корпусах более крупных размеров. Преимущество такой конструкции, кроме повышенной механической прочности, заключается в надежности электрического контакта.

Еще один тип компонентов, выпускаемых WIMA, - конденсаторы для импульсных приложений (рис. 6). Важная особенность изделий - высокая допустимая токовая нагрузка контактов. Конструкция конденсаторов серии МКР 10 содержит диэлектрическую и металлизированную с двух сторон проводящую пленку, служащую электродом. Значительно улучшенная благодаря двухсторонней металлизации электрическая проводимость контактов позволила повысить допустимый ток. Такие полезные свойства металлизированных конденсаторов, как способность самовосстановления и высокие номиналы емкости, остались неизменными.

Серия FKP 1 разработана для чрезвычайно высокой импульсной нагрузки. Конструкция конденсаторов предусматривает внутреннее последовательное соединение: электроды из металлической фольги совмещены с плавающим электродом, металлизированным с обеих сторон. С точки зрения импульсной нагрузочной способности серия FKP 1 соответствует самым высоким требованиям, предъявляемым ктакого класса изделиям.

Импульсные конденсаторы WIMA подходят для высокочастотных приложений, таких как импульсные источники питания, телевизоры, осветительные системы, аудио-и видеотехника, преобразователи в электроприводахи силовой электронике, электронные балласты. Эти изделия доступны с номиналами емкостей от 100 пФ до 47 мкФ и номинальным напряжением от 100 до 6000 В. Расстояние между выводами - от 7,5 до 52,5 мм.

Компания WIMA выпускает также помехоподавляющие конденсаторы (рис. 7), которые предназначены как для снижения электромагнитных помех, так и для защиты системы от выбросов питающего напряжения. Предлагаются устройства двух типов: на основе полипропиленовой пленки (серия МКР) и металлизированной бумаги (серия МР). Полипропиленовые конденсаторы отличаются от бумажных более высоким номиналом емкости в компактных корпусах.

Конденсаторы на основе металлизированной бумаги герметизируются стойким к воспламенению компаундом. Благодаря малой склонности бумажного диэлектрика к окислению устройства способны самовосстанавливаться даже в случае пропускания импульсов высокой мощности. Рабочий диапазон температур бумажных конденсаторов составляет от -40 до $110^{\circ} \mathrm{C}$.

Конденсаторы серий МКР и МР доступны для приложений классов X1, X2 и Y2. Устройства класса X подключаются между фазой и нейтралью или между фазами питания. 


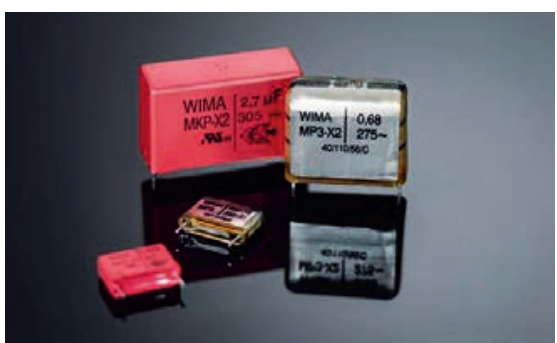

Рис. 7. Помехоподавляющие конденсаторы

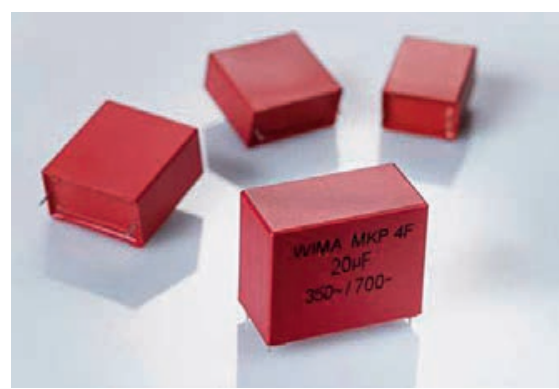

Рис. 8. Фильтрующие конденсаторы

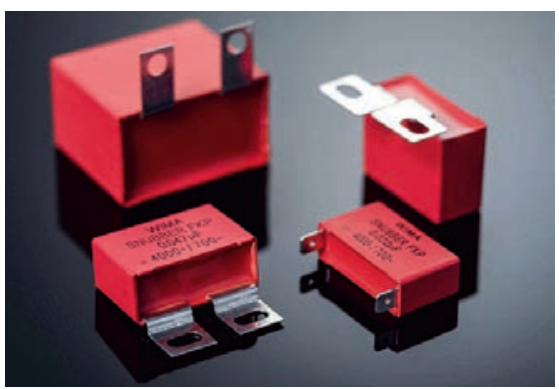

Рис. 9. Снабберы
Конденсаторы класса Ү отличаются более высоким уровнем электрической безопасности и подключаются, например, между фазовым проводом и заземленным корпусом, шунтируя изоляцию.

Для серии МКР доступны номиналы емкостей от 1000 пФ до 10 мкФ, изделия рассчитаны на номинальное напряжение от 250 до 440 В, шаг выводов - от 7,5 до 37,5 мм

Емкость конденсаторов серии МР - от 1000 пФ до 0,22 мкФ, напряжение - от 250 до 500 В, шаг выводов от 10 до 27,5 мм.

Еще один класс устройств от WIMA - фильтрующие конденсаторы (рис. 8), которые отличаются не только хорошими высокочастотными характеристикам, но и высоким максимально допустимым напряжением. Этот тип конденсаторов в общем случае должен отвечать двум требованиям: низкое сопротивление по переменному току и способность ослаблять импульсы переходного напряжения, вызванные, например, коммутацией.

Фильтрующие конденсаторы WIMA серии MKP 4F, созданные на основе металлизированной полипропиленовой пленки с низкими потерями, демонстрируют высокие допустимые высокочастотные токи, а также низкие значения эффективного последовательного сопротивления и индуктивности. Предусмотренное в них внутреннее последовательное соединение обеспечивает повышенные значения напряжения коронного разряда. Номинальное напряжение составляет от 230 до 440 В АС. Доступны конденсаторы с номиналами емкостей от 0,68 до 75 мкФ. Расстояние между выводами - от 27,5 до 52,5 мм.
Снабберы, или демпфирующие конденсаторы, предназначены для подавления индуктивных выбросов или ограничения перенапряжений при переходных процессах, возникающих при коммутации силовых устройств. Снабберы от WIMA доступны в двух сериях: МКР - на основе полипропиленовой пленки с электродами с двухсторонней металлизацией и внутренним последовательным соединением и FKP - на основе полипропиленовой пленки с самовосстановлением с электродами из металлической фольги и металлизированным внутренним последовательным соединением.

Выпускаемые WIMA снабберы (рис. 9) предназначены для импульсных высоковольтных и высокочастотных приложений, требующих чрезвычайно надежных контактов, например для схем на основе IGBT. Низкая самоиндукция достигается благодаря конструкции с торцевыми контактами. Доступны различные конфигурации контактов, в том числе 4-выводные версии и варианты с креплением контактов на плату винтами. Устройства предлагаются в огнезащитном пластиковом корпусе, соответствующем требованиям UL 94 V-0. WIMA обеспечивает крупносерийное и мелкосерийное их производство с индивидуальной конфигурацией контактов.

Для серии МКР доступны номиналы емкостей от 0,047 до 8 мкФ, номинальные напряжения от 700 до 3000 B DC, для серии FKP - 0,01-3,3 мКФ и 630-4000 B DC.

GTO-конденсаторы (поглощающие) от WIMA предназначены для подавления всплесков напряжения на тиристорах и IGBТ (рис. 10). Устройства серии GТО МКР производятся

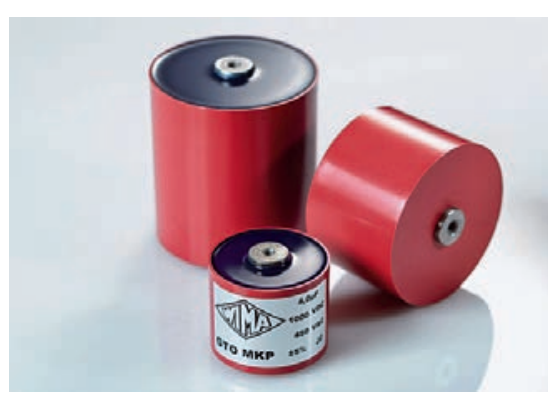

Рис. 10. GTO-конденсаторы

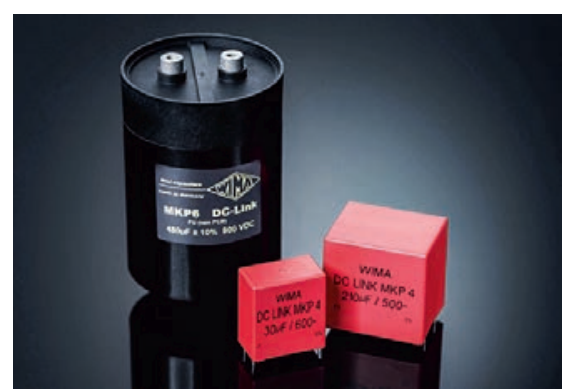

Рис. 11. Конденсаторы DC-Link

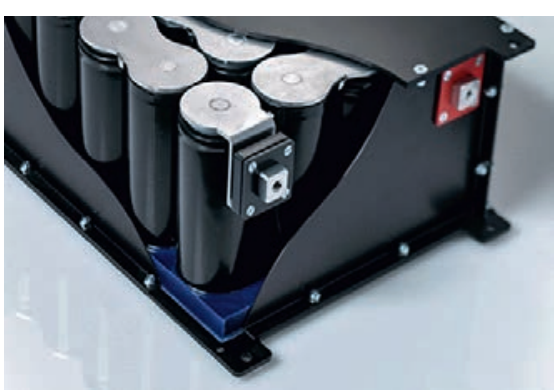

Рис. 12. Силовой блок PowerBlock 
Таблица 1. Серии конденсаторов DC-Link

\begin{tabular}{|c|c|c|c|c|}
\hline Серия & Тип корпуса & $\begin{array}{l}\text { Диапазон } \\
\text { емкостей, мкФ }\end{array}$ & $\begin{array}{l}\text { Диапазон номинальных } \\
\text { напряжений, B DC }\end{array}$ & Версия выводов \\
\hline DC-Link MKP 3 & $\begin{array}{l}\text { Цилиндрический } \\
\text { пластиковый }\end{array}$ & От 35 до 200 & От 700 до 1500 & $\begin{array}{l}\text { Винтовые крепления (с вну- } \\
\text { тренней и внешней резьбой) }\end{array}$ \\
\hline DC-Link MKP 4 & \multirow{2}{*}{$\begin{array}{l}\text { Прямоугольный } \\
\text { пластиковый }\end{array}$} & От 1 до 400 & От 400 до 1300 & \multirow{2}{*}{$\begin{array}{l}\text { Проволочные выводы } \\
\text { (2- и 4-выводные версии) }\end{array}$} \\
\hline DC-Link MKP 4S & & От 0,47 до 80 & От 450 до 1050 & \\
\hline DC-Link MKP 5 & $\begin{array}{l}\text { Цилиндрический } \\
\text { пластиковый }\end{array}$ & От 16 до 260 & От 500 до 1300 & Проволочные выводы \\
\hline DC-Link MKP 6 & $\begin{array}{l}\text { Цилиндрический } \\
\text { алюминиевый }\end{array}$ & От 75 до 4920 & От 600 до 1500 & $\begin{array}{l}\text { Винтовые крепления под M6, } \\
\text { крепежный болт под M12 }\end{array}$ \\
\hline DC-Link HC & $\begin{array}{l}\text { Прямоугольный } \\
\text { пластиковый }\end{array}$ & От 140 до 8250 & От 450 до 1500 & $\begin{array}{l}\text { Плоские выводы (возможна } \\
\text { заказная конфигурация выводов) }\end{array}$ \\
\hline DC-Link HY & $\begin{array}{l}\text { Прямоугольный } \\
\text { пластиковый }\end{array}$ & 500 & 450 & $\begin{array}{l}\text { Плоские выводы, винтовое } \\
\text { крепление }\end{array}$ \\
\hline
\end{tabular}

по технологии на основе металлизированной полипропиленовой пленки с самовосстановлением и инкапсулируются в пластиковый корпус цилиндрической формы, который заливается огнеупорным полиуретановым композитом. Такая конструкция обеспечивает очень малую самоиндукцию, высокую механическую прочность, ударо- и виброустойчивость, большую допустимую нагрузку по току, практически неограниченный срок службы.

Области применения этихустройств - высоковольтные приложения, такие как преобразователи в станциях генерирования электроэнергии или в оборудовании для транспорта, например в подъемных устройствах, электроприводах в поездах, кранахи т.д.

Емкости GTO МКР-конденсаторов от WIMA - от 1 до 100 мКФ, номинальное напряжение - от 400 до 2000 B DC. Выпускаются версии с резьбовым монтажом под М6 и $\mathrm{M} 8$.

Еще один класс устройств производства WIMA - конденсаторы DC-Link (рис. 11), предназначенные для шин постоянного тока в преобразователях высокой мощности (в ветроэнергетических установках, инверторах солнечных батарей ит.д.). Вследствие возрастающихтребований к надежности такого оборудования эти изделия все шире применяются вместо электролитических конденсаторов. Для выпускаемых на основе полипропиленовой пленки с низкими потерями конденсаторов DC-Link характерны более высокая допустимая нагрузка по току, а также меньший саморазогрев на высоких частотах по сравнению с электролитами. В семейство DC-Link входит несколько серий (табл. 1).

Устройства отличаются высоким отношением номинала емкости к габаритам, большим номинальным напряжением, очень малым тангенсом угла потерь, очень высоким сопротивлением изоляции, длительным сроком службы, устойчивостью к ударной и вибронагрузке, механической прочностью. Неполярная конструкция конденсаторов DC-Link, оснащенных контактами повышенной надежности, упрощает их применение.

Силовые блоки WIMA PowerBlock (рис. 12) - это двухслойные модульные блоки суперконденсаторов с очень высокой емкостью от 62 до 500 Ф и номинальным напряжением от 16 до 125 B DC. Они предназначены для быстрой подачи питания, в частности, чтобы обеспечить пиковую мощность, а также для защиты батарей в различном промышленном и транспортном оборудовании, например в строительной технике, генераторах электроэнергии, грузовых автомобилях, автобусах, поездах, беспилотных летательных аппаратах, ИБП и др. Устройства пропускают больший ток (до 1900 А) за короткое время и не требуют обслуживания. По запросу доступны заказные варианты номиналов емкости, напряжения и габаритов этих изделий

\section{ЗАКЛЮЧЕНИЕ}

Номенклатура конденсаторов WIMA перекрывает весь спектр типономиналов, емкостей и напряжений, востребованных в самых разных отраслях - от автомобильной электроники и систем освещения до промышленного и телекоммуникационного оборудования. Изделия соответствуют самым строгим требованиям по качеству и надежности. Для клиентов доступны также заказные варианты исполнения устройств.

За более подробной технической информацией о продукции WIMA обращайтесь в холдинг «Золотой Шар» - к официальному дистрибьютору WIMA в России. Для пользователей также доступен русскоязычный сайт www.wima.ru. 


\section{Загляни \\ в сердце}

технологий 